\title{
CHEMICAL REACTIONS IN SOLID POLYMERIC SYSTEMS. PHOTOMECHANICAL PHENOMENA
}

\author{
G. Smets and F. De Blauwe
}

\author{
Laboratory of Macromolecular Chemistry, K. Universiteit Leuven, \\ Louvain, Belgium
}

\begin{abstract}
Poly(ethyl acrylates) crosslinked with $0.5-1$ mole- $\%$ of photochromic bis(spirobenzopyran dimethylacrylate) show in the solid state a photomechanical behaviour. On irradiation, contraction (more than two per cent) occurs in isothermal conditions, while in the dark, length-recovery takes place, the process being reversible. The dependence of this photocontractile behaviour under constant stress on temperature, and inversely at constant temperature, on increasing stress has been examined by plotting the relative shrinking $\Delta L / L$ as a function of time. This photomechanical effect is much more pronounced for samples swollen in benzene. The photostationary relative contraction of copolymer $\mathrm{C}$ increases with the relative elongation $\lambda=L / L_{0}$ at low stresses, passes through a maximum for $\lambda=2.3$, and then decreases. This photomechanical shrinking is interpreted in terms of an increase of entropy of the polymer chains due to the isomerization of the rigid bis-spiro-structure into the planar merocyanine one. The photochromic behaviour of copolymer $\mathrm{C}$, unstretched and stretched (50 per cent) has also been followed at different temperatures. Stretching causes a strong decrease of decoloration rate constants, being one-third of that in unoriented state.

When, in contrast, poly(ethyl acrylate) is crosslinked with ethylene glycol dimethacrylate and carries pendant similar photochromic groups $(0.7$ per cent), no effect on the photochrome and photomechanical behaviour can be shown. The involvement of the strained biphotochromes in the crosslinks is thus required.
\end{abstract}

\section{INTRODUCTION}

It is generally assumed that compounds which are incorporated in a rigid matrix, or are bound to a polymeric substrate, are subject to severe restrictions of their translation and rotation possibilities. On account of differences of chain-segment mobility these restrictions must be most pronounced in the rigid glassy state. Above the glass transition temperature $T_{\mathrm{g}}$ i.e. in the rubbery region, the matrix behaves as a highly viscous medium; possibilities for translation and rotation increase strongly and progressively approach those observed in a highly viscous solution.

Therefore, important changes in reaction rate have to be expected if the reactions are carried out in the solid state below and above $T_{g}$ as far as sufficiently important translation or rotation phenomena are involved. On 
the basis of such considerations, we have discussed recently ${ }^{1}$ reversible photochromic isomerization phenomena, especially the cis-trans-isomerization of aromatic azo-derivatives and the ring opening/closure of spirobenzopyran derivatives, for which most quantitative experimental data are available, for reactions in the solid state $e^{2-4}$.

Similarly, racemization of optically active polymers and some bonddissociation reactions in solid polymeric matrices were considered ${ }^{5}$. It is clearly shown that the efficiencies and rates of reactions carried out in polymeric matrices often differ very strongly in the glassy and in the rubbery state, on account of large differences in chain-segment mobility, and that these effects are most strongly pronounced when the reactive groups are bound chemically to the polymer molecule, if compared to mixtures in polymeric matrices. In the present paper we focus attention mainly on a new aspect of reactions in the solid state, namely the photomechanical properties of some photochromic polymeric systems, which were observed only recently.

In these reactions light energy is apparently converted into mechanical work, and causes a reversible contractile behaviour of the systems.

Photomechanical properties of polymers have been described previously by Agolini and Gray ${ }^{6}$ and by Van der Veen and Prins ${ }^{7-9}$. Although the two polymeric systems studied by these authors are quite different, the reported photocontractile behaviours are in both cases related to the cis-transisomerization of aromatic azo-groups. On the other hand, our data were based exclusively on the photochromism of spirobenzopyran derivatives. We will consider successively the two types of photochromic principles and their eventual photomechanical effects on polymeric systems.

\section{PHOTOCONTRACTION OF POLYMERIC AROMATIC AZO-DERIVATIVES}

It is well known that under irradiation of aromatic azo-derivatives trans $\rightleftarrows$ cis-isomerization occurs, and moreover that a thermal cis $\rightarrow$ transisomerization takes place, the trans-isomer being more stable than its cisisomer. Since the cis-isomer is strongly hypsochromic with respect to the trans-isomer on account of a lack of coplanarity of the molecules, the rate of trans $\rightleftarrows$ cis isomerization can easily be followed by optical-density measurements.

Agolini and Gray ${ }^{6}$ prepared a poly-(4,4'-diphenylazopyromellitimide) by two-step condensation of 4,4'diaminoazobenzene with pyromellitic dianhydride [formula (a)].

The polymer is semicrystalline, has a repeat unit of $18.3 \AA$ which corresponds to the trans-azo-configuration; this restricts the cis-configuration,

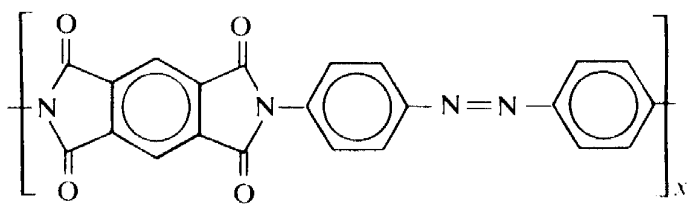


when formed, to the amorphous regions. These azo-aromatic polyimides show a reversible thermal and photocontractile behaviour, which seems to be associated with trans-cis-isomerization. Measurements at constant stress carried out at $200^{\circ} \mathrm{C}$ indicate a deformation of about 0.6 per cent. On the other hand, in constant-length experiments the stress imposed on a film during irradiation increases with time, the effect being small but real. Considering that the half lives of this contractile process are similar at room temperature and at $200^{\circ} \mathrm{C}$ (around 40 minutes) indicating a negligible activation energy, while the isomerization of azo-compounds in solution shows an enthalpy of activation around $20 \mathrm{kcal}$, the authors admit that the rate of contraction or expansion is controlled rather by some viscoelastic properties of the polymer (with low $E_{\mathrm{a}}$ ) than by the rate of cis-trans-isomerization of the azo-linkage. This interpretation seems very likely, if one refers to the data obtained by Paik and Morawetz ${ }^{3}$ for such analogues systems as polyamides and polyesters containing azo-aromatic groups in the polymeric backbone.

Indeed, the photostationary fraction of cis-isomer in polybis-phenol-Aisophthalate, containing 1.4 per cent of $p, p^{\prime}$-azobenzenedicarboxylic units, amounts only 0.025 in the glassy state instead of 0.45 in chloroform solution. Such small degree of conversion of trans into cis-isomer in the glassy state could hardly account for the contraction effect as described above.

On the other hand, it can hardly be postulated that this photomechanical effect results from a rubbery behaviour of this polyimide at a temperature much lower than $T_{\mathrm{g}}$.

Van der Veen and Prins were interested in a completely different system, namely membranes of 2-hydroxyethyl methacrylate cross-linked with ethylene glycol dimethacrylate (1.1 per cent). A small amount of the watersoluble dyestuff, chrysophenin (formula b), was added to the membrane swollen in water, the ratio chrysophenin/hydroxyethyl methacrylate unit being $1 / 400$.

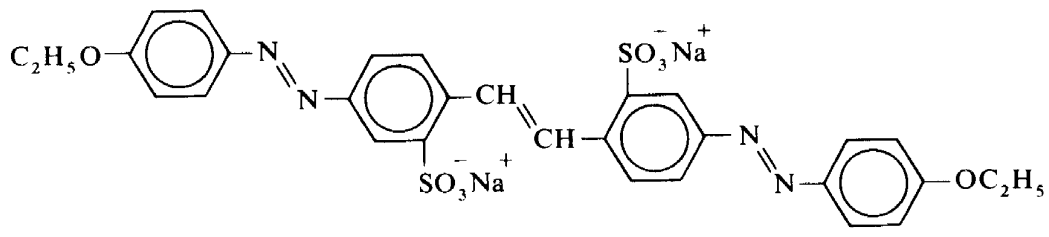

(h)

Under irradiation (10 minutes) the gel contracts for 1.2 per cent ; in the dark it recovers the original dimensions. The rate of recovery is a function of the temperature, and parallels the increase of optical density of chrysophenin at $400 \mathrm{~nm}$. In order to explain this contractile behaviour, the authors assume a change of conformation of the polymer backbone, resulting from a solubility difference of the trans and the cis-isomers in the hydrophobic part of the macromolecule.

\section{PHOTOCONTRACTION OF SPIROBENZOPYRAN NETWORKS}

Spirobenzopyran derivatives undergo, under ultra-violet irradiation, a 
cabon-oxygen bond scission followed by cis-trans-isomerization during which deeply coloured open-ring merocyanines are formed (equation c).
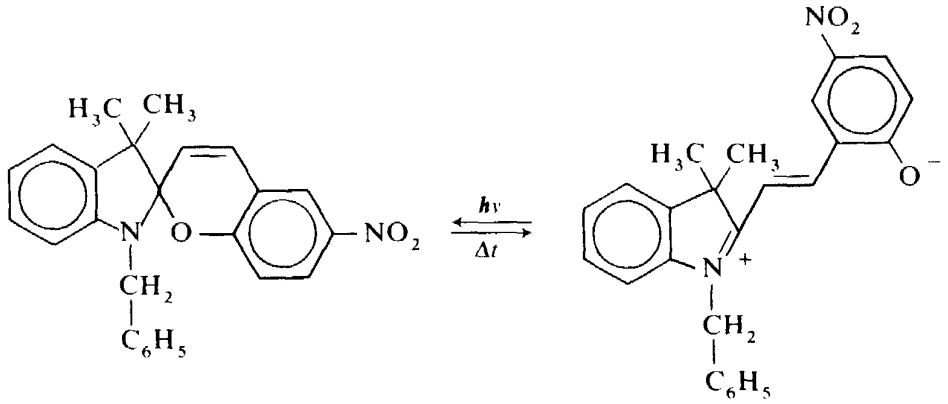

1-Benzyl-6'-nitro-DIPS*

These coloured species revert to the colourless component by a thermal as well as photochemical process, during which different intermediates are involved ${ }^{10}$. The rate of the thermal decolouration of DIPS-merocyanines is strongly dependent on the glass-transition temperature of the matrices in which they are embedded, and especially when the DIPS is bound to the polymer chain. The effect is most pronounced in photochromic polycondensates containing a bifunctional DIPS-photochrome within the polymer backbone; it makes it possible to regulate the photoresponsive behaviour of the colourless material, as well as its thermal decolouration.

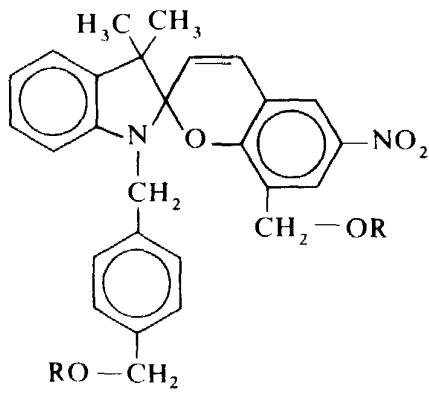

$$
\mathrm{R}=\left[\mathrm{CO}-\left(\mathrm{CH}_{2}\right)_{5}-\mathrm{CO}-\mathrm{O}-\mathrm{C}_{6} \mathrm{H}_{4}-\left.\right|_{\text {i.e. (polyester) }} ^{\mathrm{C}}-\mathrm{C}_{6} \mathrm{H}_{4}-\mathrm{O}\right]_{x}
$$

An example is represented by formula (d) of a photochromic polyester containing 3 moles-\% of 1-(p-hydroxymethylbenzyl)-8-hydroxymethyl-6nitro-DIPS within poly-bisphenol-A-pimelate sequences ${ }^{4}$.

The much greater sensitivity of the DIPS-compounds to $T_{\mathrm{g}}$ and secondary transition phenomena than the aromatic azo-derivatives must be related to the rigidity of the spiro(benzopyranindoline) linkage and to the bulkiness

* The acronym DIPS is used for 3,3-dimethylspiro-12H-1-benzopyran-2.2'-indoline). 
of the DIPS portion that is obliged to rotate around the $\mathrm{C}=\mathrm{C}$ double bond in order to achieve the trans-configuration.

It seems therefore very attractive to incorporate DIPS-compounds as photosensitive elements within a rubbery material [crosslinked polyethyl acrylate] and to observe the photochemical contractile behaviour that their presence may induce. We will consider successively $(a)$ the photomechanical behaviour of photochromic DIPS-networks and $(b)$ their photochromism in oriented networks.

(a) Photomechanical behaviour of crosslinked photochromic poly(ethyl acrylates)

Copolymers of ethyl acrylate and bis(DIPS methacrylate) (formula e) were prepared in the presence of azobis-isobutyronitrile or isopropyl peroxydicarbonate as initiator (see Table 1). The copolymers were purified by repeated extraction of the thread- or sheet-like samples with benzene, then unswollen by addition of hexane and dried in vacuum at $45^{\circ} \mathrm{C}$.

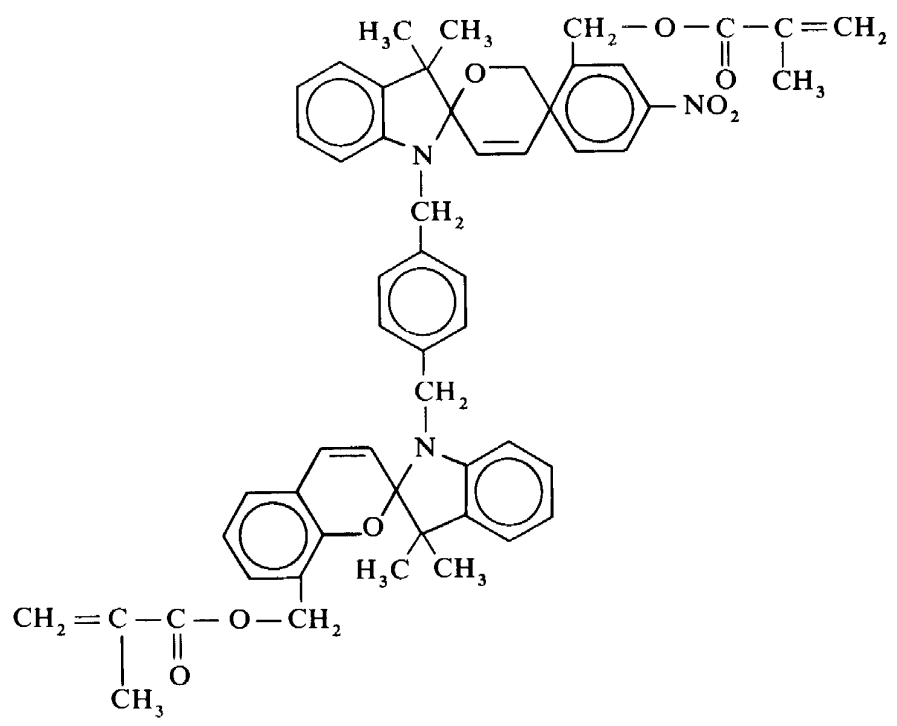

The content of bis(DIPS methacrylate) in the monomer mixture is 0.5 mole- $\%$ ( 4.5 weight- $\%$ ) for copolymers A, B, C, and $1 \mathrm{~mol}-\%$ for copolymer $\mathrm{D}$.

The glass-transition temperatures of all four copolymers were around -18 to $-15^{\circ} \mathrm{C}$. Their photomechanical behaviour was studied under constant stress (load) by following at constant temperature the length contraction as a function of time. During irradiation contraction occurs; in the dark length recovery takes place, although at a slower rate than the shrinking. After a few light/dark cycles the progress becomes entirely reversible; during the first cycles, dark recovery exceeds the photocontraction on account of a progressive equilibration of the polymer network. Therefore before irradiation all samples were equilibrated under stress during 18 hours at the temperature of measurement. 


\section{G. SMETS AND F. DE BLAUWE}

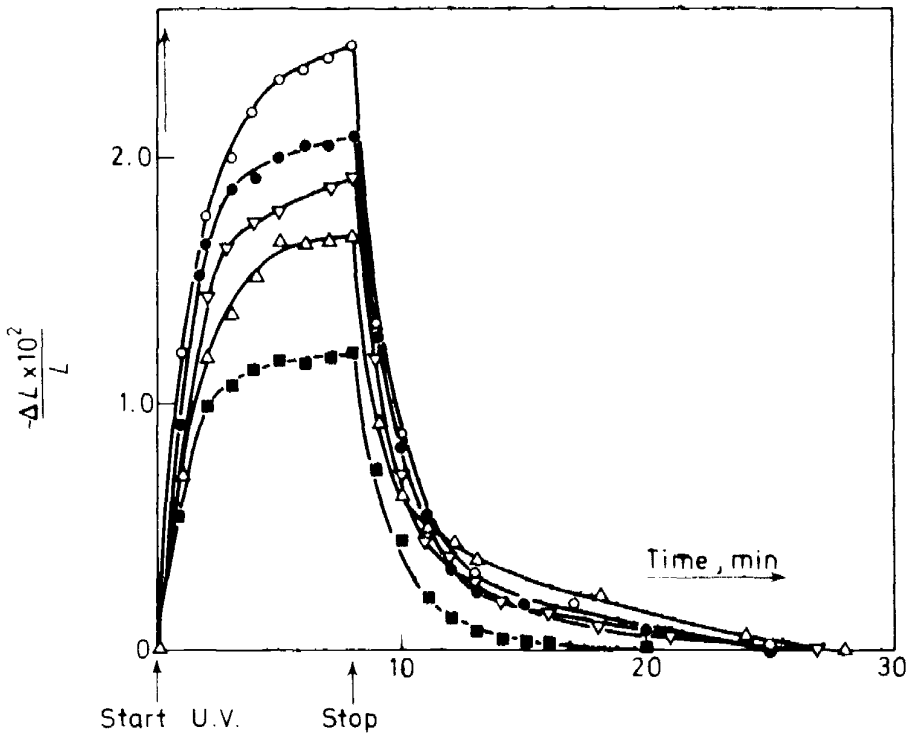

Figure 1. Photomechanical behaviour of copolymer A (dry). Influence of the temperature and stress

\begin{tabular}{ccll}
\hline & Temperature & $\mathrm{mm}$ & load \\
\hline$\triangle$ & 15 & 44.5 & 21.9 \\
$\triangle$ & 29.6 & 44 & 21.9 \\
$\bullet$ & 45 & 42 & 21.9 \\
$\nabla$ & 15 & 22 & 35.7 \\
\hline
\end{tabular}

Table 1. Synthesis of photochromic poly(ethyl acrylate) networks

\section{Reaction mixture in mmoles}

\begin{tabular}{|c|c|c|c|c|c|c|c|}
\hline Polymer & bis(DIPS) & $\begin{array}{l}\text { ethyl } \\
\text { acrylate }\end{array}$ & Initiator & $\begin{array}{l}\text { solvent } \\
(\mathrm{ml})\end{array}$ & $t / 0 \mathrm{C}$ & time/h & Sample \\
\hline A & 0.05 & 9.95 & $0.02 \mathrm{AIBN}$ & $\begin{array}{l}0.5 \\
\text { benzene }\end{array}$ & 80 & 18 & $\begin{array}{l}\text { thread } \\
1.69 \mathrm{~mm} \text { diam. }\end{array}$ \\
\hline B & 0.1 & 19.9 & 0.05 IPP & ${ }^{4} \mathrm{DMF}$ & 45 & 48 & $\begin{array}{l}\text { sheet } \\
0.48 \mathrm{~mm} \text { thickness }\end{array}$ \\
\hline C & 0.2 & 39.8 & 0.05 IPP & ${ }^{4}$ benzene & 37 & 48 & $\begin{array}{l}\text { sheet } \\
0.69 \mathrm{~mm} \text { thickness }\end{array}$ \\
\hline $\mathrm{D}$ & 0.4 & 39.8 & $0.05 \mathrm{IPP}$ & 4 benzene & 37 & 48 & $\begin{array}{l}\text { sheet } \\
0.56 \mathrm{~mm} \text { thickness }\end{array}$ \\
\hline$S$ & $\begin{array}{l}0.2 \text { EGDMA }^{b} \\
0.4 \text { (DIPS) }_{1}{ }^{c}\end{array}$ & 39.8 & 0.05 IPP & ${ }^{4}$ benzene & 37 & 48 & $\begin{array}{l}\text { sheet } \\
0.49 \mathrm{~mm} \text { thickness }\end{array}$ \\
\hline
\end{tabular}

\footnotetext{
- AIBN : azobis-isobutyronitrile; IPP isopropyl peroxydicarbonate

b FGDMA : ethylene glycol dimethacrylate

(DIPS), indicates: 1-henzyl-8-methacroyloxymethyl-6-nit ro-DIPS
} 


\section{CHEMICAL REACTIONS IN SOLID POLYMERIC SYSTEMS}

Figure 1 shows the photocontractile behaviour of copolymer A under constant stress at different temperatures, and at constant temperature under increasing stresses. Shrinking and lengthening are indicated in $[-\Delta L / L]$ $\times 10^{2}$ where $L$ is the length of the loaded sample after complete equilibration. The photomechanical effect increases with decreasing temperature and with decreasing stress, a photostationary state being reached after about eight minutes. After cutting off the light the elongation process (followed in diffuse light) takes about half an hour.

Copolymer B was examined in the dry state and swollen in benzene. In contrast to copolymer A, the relative contraction increases with increasing load (Figure 2). In swollen state ( 35 per cent benzene), the photomechanical

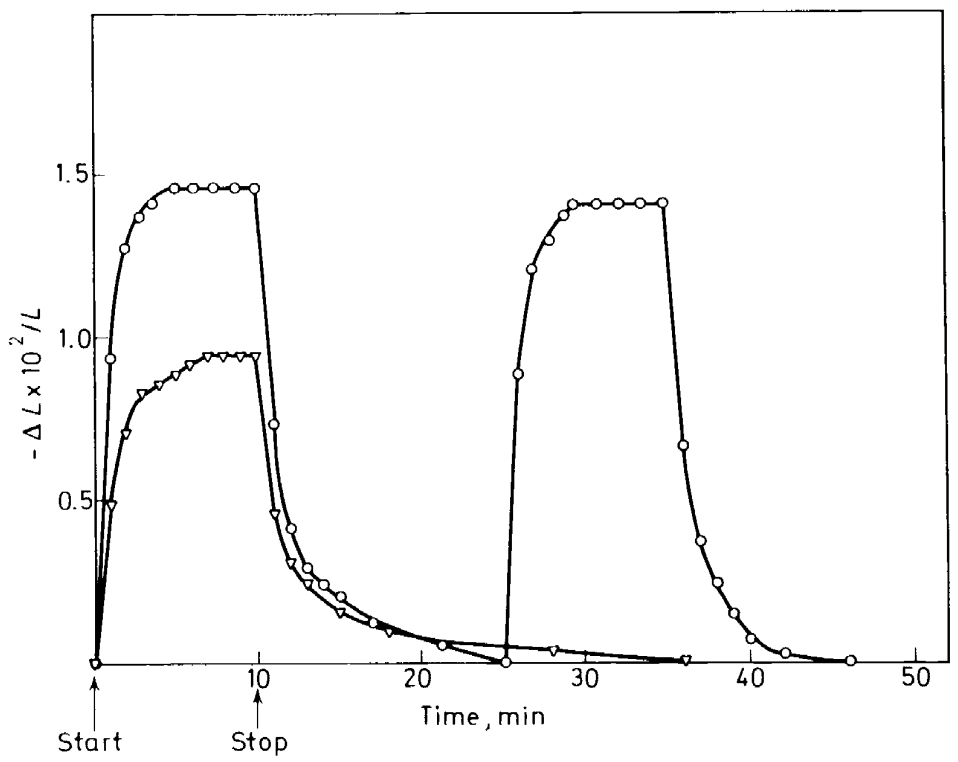

Figure 2. Photomechanical behaviour of copolymer B (dry). Influence of the stress

$$
\begin{array}{ccr}
\text { film thickness } 0.48 \mathrm{~mm} & \text { load } 18.5 \mathrm{~g}\left(25^{\circ} \mathrm{C}\right) & \nabla \\
\text { width } & 5.5 \mathrm{~mm} & 26.8 \mathrm{~g}\left(27^{\circ} \mathrm{C}\right)
\end{array}
$$

effect is markedly increased, one-tenth of the load used with the dry sample being already sufficient for 2.3 per cent contraction (Figure 3). By increasing the stress, the swollen sheet-like sample contracts more than 6.5 per cent, then breaks.

The different photocontractile responses of copolymers A and B towards the stress suggest the existence of an optimum stress for which a maximum photocontraction will be obtained. Therefore, copolymers $\mathrm{C}$ and $\mathrm{D}$ were prepared in the same experimental conditions, but differ only in their bis(DIPS methacrylate) content ( 0.5 and 1 mole- \% respectively). Figure 4 shows the photostationary relative contraction of the dry samples in vacuum after ten minutes irradiation in function of the relative elongation $\lambda=L / L_{0}$, i.e. with increasing load. The reproducibility of the measurements is fairly 


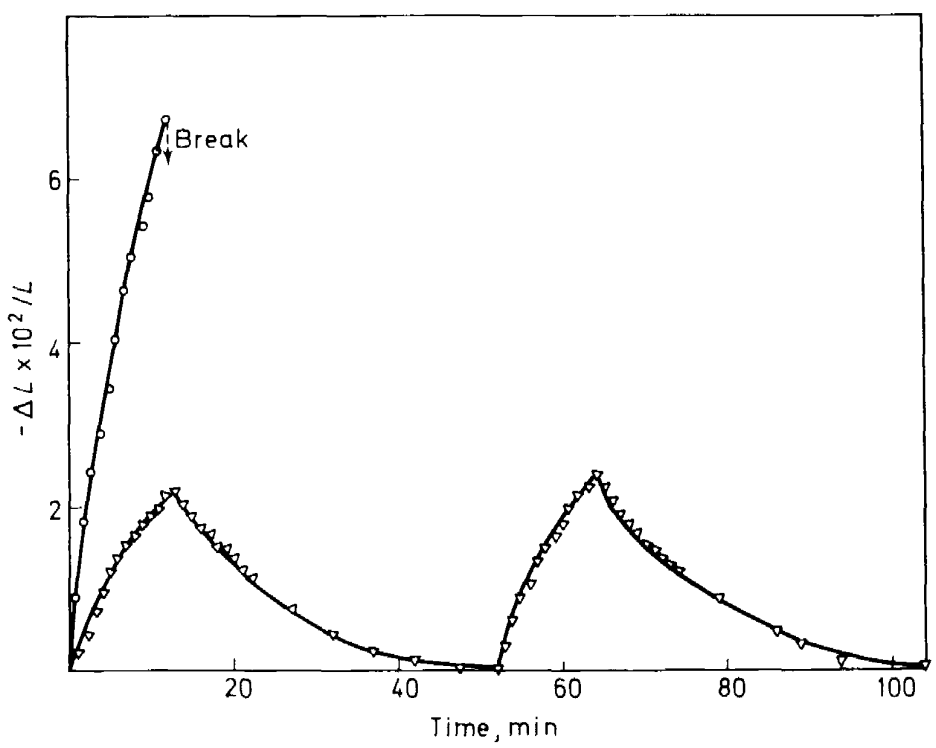

Figure 3. Photomechanical behaviour of copolymer B, swollen in benzene $(30-40 \%)\left(27^{\circ} \mathrm{C}\right)$

load: $2.7 \mathrm{~g} \nabla$

$4.9 \mathrm{~g} \quad \mathrm{O}$

good, as can be seen in Figure 4. The weights along the curves indicate the loads necessary to obtain the elongation as given in abcissae.

The maximum photocontraction (two per cent) of polymer $\mathrm{C}$ is obtained at a relative elongation of 2.3-2.5. At the same $\lambda$-value, the photocontractile response of copolymer D exceeds markedly that of the less cross-linked copolymer $\mathrm{C}$; it was however not possible to measure its maximum value, on account of rupture of the sample by further weight increase (higher elongation). Beyond the optimum $\lambda$-value, the photocontractile effect decreases with increasing stress.

In order to interpret these data, it must first be pointed out that the photocontractile behaviour cannot be attributed to a temperature increase of the samples during irradiation. Experimentally it was indeed verified that the temperature variation $\Delta t$ measured in situ never attains $0.5^{\circ} \mathrm{C}$, while a two per cent length contraction, as observed at $15^{\circ} \mathrm{C}$ (polymer $\mathrm{A}$ ), would necessitate a temperature increase $\Delta t$ of $20^{\circ} \mathrm{C}$, i.e. $35^{\circ} \mathrm{C}$. Moreover, the photomechanical effect remains unchanged if the experiments are carried out in a vacuum or in air.

On the other hand it is admitted that the volume variation of the sample is very small, so that the term $p \mathrm{~d} V$ is negligible and the work to stretch by the force $f$ reduces to :

$$
\mathrm{d} W=f \mathrm{~d} l-\mathrm{p} \mathrm{d} V \approx f \mathrm{~d} l
$$

The variation of internal energy $\mathrm{d} E$ is thus equal to

$$
\mathrm{d} E=f \mathrm{~d} l+T \mathrm{~d} S
$$




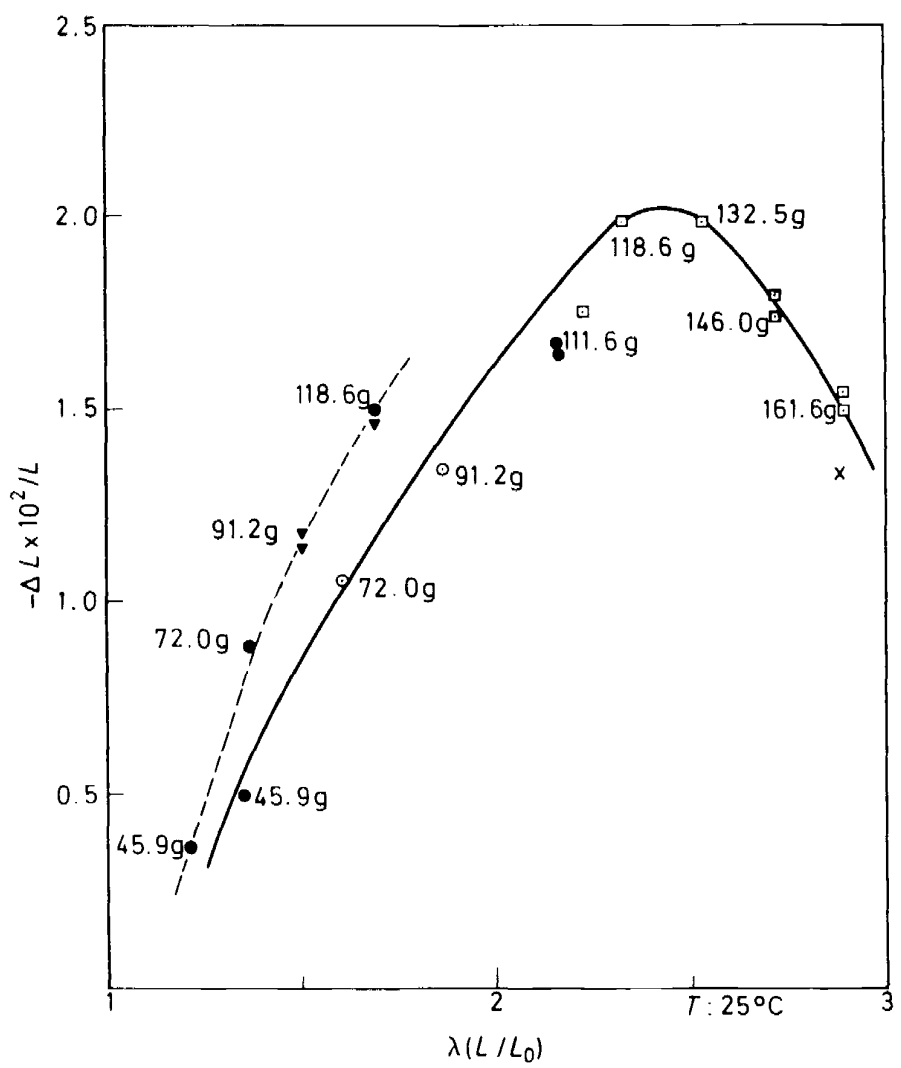

Figure 4. Photocontraction of copolymers $\mathrm{C}$ and $\mathrm{D}$. Influence of the relative elongation $L / L_{0}$

\begin{tabular}{lll}
\hline \multicolumn{1}{c}{ copolymer } & \multicolumn{1}{c}{ C } & \multicolumn{1}{c}{ D } \\
\hline mole $\%$ bis(DIPS methacrylate) & 0.5 & 1 \\
film width mm & 5.15 & 5.15 \\
& $0.69 \circ$ & $0.56 \nabla$ \\
& $0.67 \square$ & \\
\hline
\end{tabular}

Since, in an isothermal process, $[\mathrm{d} E / \mathrm{d} l]_{T}$ is very small with respect to $T[\mathrm{~d} S / \mathrm{d} l]_{T}$ and remains practically constant up to 300 per cent elongation, it follows that :

$$
f=\left[\frac{\mathrm{d} E}{\mathrm{~d} l}\right]_{T}-T\left[\frac{\mathrm{d} S}{\mathrm{~d} l}\right]_{T} \approx-T\left[\frac{\mathrm{d} S}{\mathrm{~d} l}\right]_{T}
$$

The stretching of a rubber by an external force varies therefore essentially the entropy of the polymer by decreasing the chain-segment mobility. The length variation of the samples is therefore the resultant of the downwards stretching force, i.e. the weight attached to the sample, and the opposite upwards force due to entropy increase. In all the polymers, the cross-links 


\section{G. SMETS AND F. DE BLAUWE}

are bis-photochromic units, which are very rigid on account of the two $s p^{3}$ spiro carbon atoms which keep the two DIPS units perpendicular to each other. On irradiation, these units are transformed into planar merocyanines which are more mobile and favourably affect the mobility of the neighbouring chain segments. As a consequence, the entropy of the system increases on irradiation, and contraction occurs (if the entropy contribution exceeds that of the stretching force). By increasing the temperature the relative importance of the entropy contribution becomes smaller, and the contraction is less pronounced.

The photostationary contraction increases with increasing elongation, as long as $\lambda$ remains below its optimum value; this is the case for the measurements with copolymers $\mathrm{B}$ and $\mathrm{C}$ and for copolymer $\mathrm{D}$ below $\lambda=2.5$.

Above the optimum value of $\lambda$, the photostationary contraction decreases with increasing elongation: this behaviour is shown by copolymer $\mathrm{D}$ above $\lambda=2.5$ and by copolymer $\mathbf{A}$, which was synthesized under experimental conditions, very different from those used for the other copolymers.

\section{(b) Photochromic behaviour of oriented crosslinked poly(ethyl acrylate)}

The photochromic behaviour of a film of copolymer $\mathrm{C}$ has been examined in oriented ( 50 per cent elongation) and unstretched states by following the rate of decolouration at different temperatures. The variation of optical density as a function of time shows, in both oriented and unoriented samples, an initial step, which is about seven times greater than the second one at a temperature below $40^{\circ} \mathrm{C}$. The existence of two open-ring merocyanines which decolourize independently of each other, following first-order kinetics, was indicated mainly because the shape of the absorption band changes noticeably with time, and its maximum absorption wavelength shifts progressively from 586 to $562 \mathrm{~nm}$ (Figure 5). The orientation of the polymer chain due to 50 per cent elongation of the sample exercises a strong influence on the rate constants for decolouration of both isomers, which are 2.5 to 3 times smaller than those for the unoriented sample. The kinetic parameters are given in Table 2, where $k_{1}$ and $k_{2}$ are the calculated rate constants of the two decolouration steps. The corresponding Arrhenius diagrams are reproduced in Figure 6.

The decrease in decolouration rate on stretching the sample is attributed to the important decrease of chain-segment mobility and demonstrates clearly the photosensitivity of DIPS-photochromes to chain orientation.

It is noteworthy that the bis(DIPS-methacrylate) dissolved in ethyl isobutyrate [low molecular weight homologue of poly(ethyl acrylate)] decolourizes about 200 times faster at $32^{\circ} \mathrm{C}$ than when it is incorporated into a rubbery network. This strong effect is due to the high internal viscosity of the network as compared to the solution, and agrees with a general statement ${ }^{1}$. Its activation energy of decolouration $E_{\mathrm{a}}=23.3 \mathrm{kcal} \mathrm{mol}^{-1}$ is nevertheless only slightly lower than that of the corresponding films.

In copolymer C, the bis(DIPS methacrylate) was used as the crosslinking agent for the rubbery poly(ethyl acrylate) network. It is attractive to compare copolymer $\mathrm{C}$ with a copolymer network in which the DIPS-units should be present only as pendant side-groups. Therefore, copolymer $\mathrm{S}$ has been prepared under the same experimental conditions as copolymer $\mathrm{C}$ (see Table 1); the crosslinking agent however was ethylene glycol dimethacrylate 
CHEMICAL REACTIONS IN SOLID POLYMERIC SYSTEMS

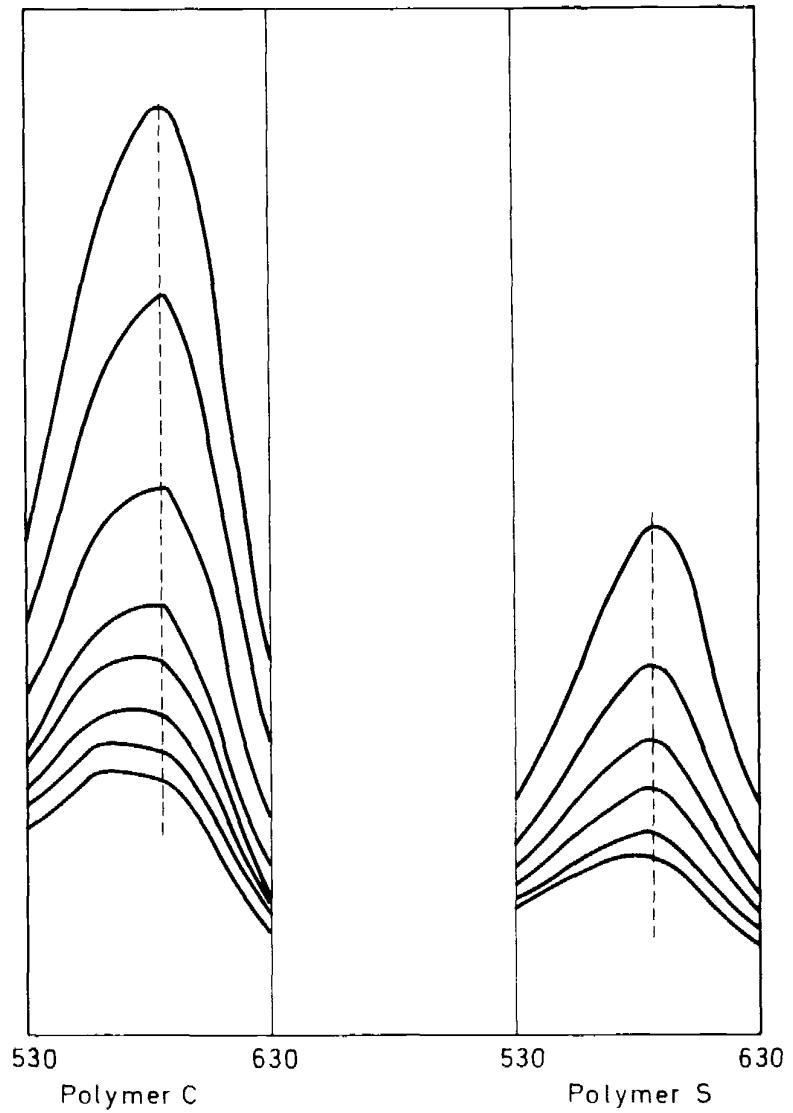

Figure 5. Variation of absorption band of copolymer $\mathrm{C}$ and copolymer $\mathrm{S}$ with time at $25^{\circ} \mathrm{C}$.

Table 2. Decolouration rate constants of copolymer $\mathrm{C}$ in the solid state

\begin{tabular}{|c|c|c|c|c|}
\hline \multirow{3}{*}{$t /{ }^{\circ} \mathrm{C}$} & \multicolumn{4}{|c|}{ rate constants in s $\mathrm{s}^{-1} \times 10^{3}$} \\
\hline & \multicolumn{2}{|c|}{ unstretched } & \multicolumn{2}{|c|}{$50 \%$ elongation } \\
\hline & $k_{1}$ & $k_{2}$ & $k_{1}$ & $k_{2}$ \\
\hline 26.3 & 2.0 & 0.3 & 0.7 & 0.12 \\
\hline 32 & 4.6 & 0.74 & 1.5 & 0.3 \\
\hline 40 & 14 & 2.3 & 5.2 & 1.2 \\
\hline 50 & 38 & 7.8 & 13 & 3.8 \\
\hline 60 & 96 & 22 & 39 & 12 \\
\hline$E_{\mathrm{a}} \mathrm{kcal} \mathrm{mol}^{-1}$ & 22.6 & 25.3 & 23.3 & 27.2 \\
\hline $\log P Z$ & 13.9 & 15 & 13.9 & 16 \\
\hline$\Delta H^{*}$ & 22.0 & 24.7 & 22.7 & 26.5 \\
\hline$\Delta S^{*}$ & 2.8 & 8.1 & 3.0 & 12.0 \\
\hline
\end{tabular}




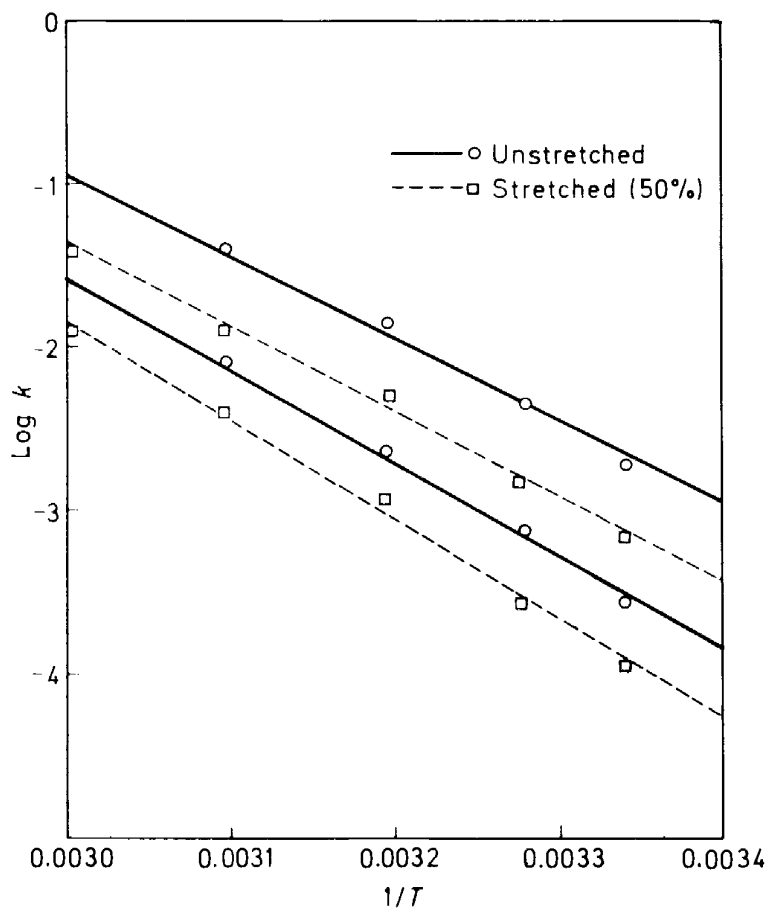

Figure 6. Arrhenius diagram of copolymer C. Influence of chain orientation.

and a monofunctional DIPS methacrylate, namely the 1-benzyl-8-methacroyloxymethyl-6-nitro-DIPS, was used together with ethyl acrylate as comonomer. The schematic structures of both copolymers are represented in Figure 7.

Both copolymers $\mathrm{C}$ and $\mathrm{S}$ have an equivalent value of $\bar{M}_{\mathrm{c}}$, the molecular weight between two successive crosslinks ( 27300 and 27200 respectively) as

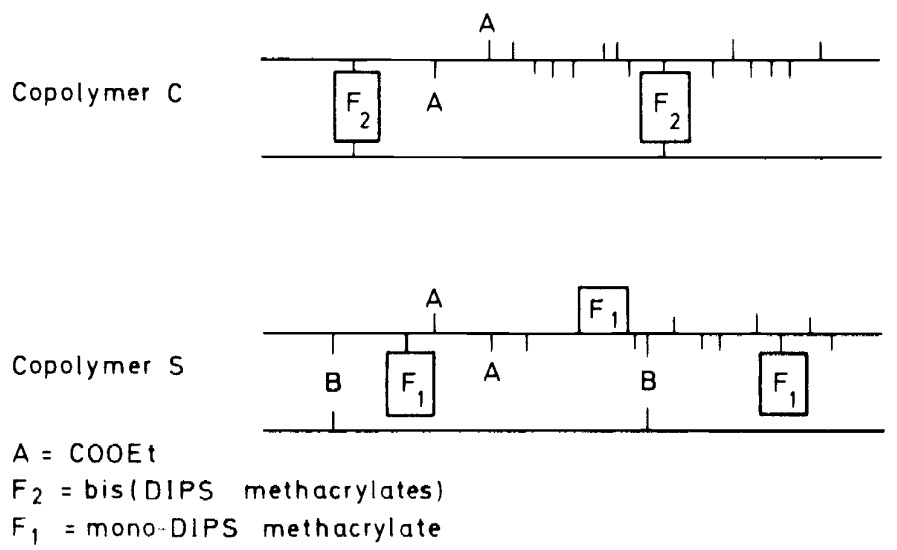

Figure 7. Schematic structures of copolymers $\mathrm{C}$ and S. 
determined by equilibrium swelling experiments ${ }^{11}$. On the basis of nitrogen analyses, the molar content of bisphotochrome in copolymer $\mathrm{C}$ amounts to $0.68 \mathrm{~mole}-\%$, that of monophotochrome in copolymer $\mathrm{S}$ to $0.73 \mathrm{~mole}-\%$. The decolouration rates of copolymer $\mathrm{S}$ were determined for the unstretched state and at 40 and 65 per cent elongations. In contrast to copolymer $\mathrm{C}$, the decolouration reaction obeys strictly first-order kinetics, and the rate constants are independent of the chain orientation, as can be seen from Table 3.

Table 3. Decolouration rate constants of copolymer $\mathbf{S}$ in the solid state

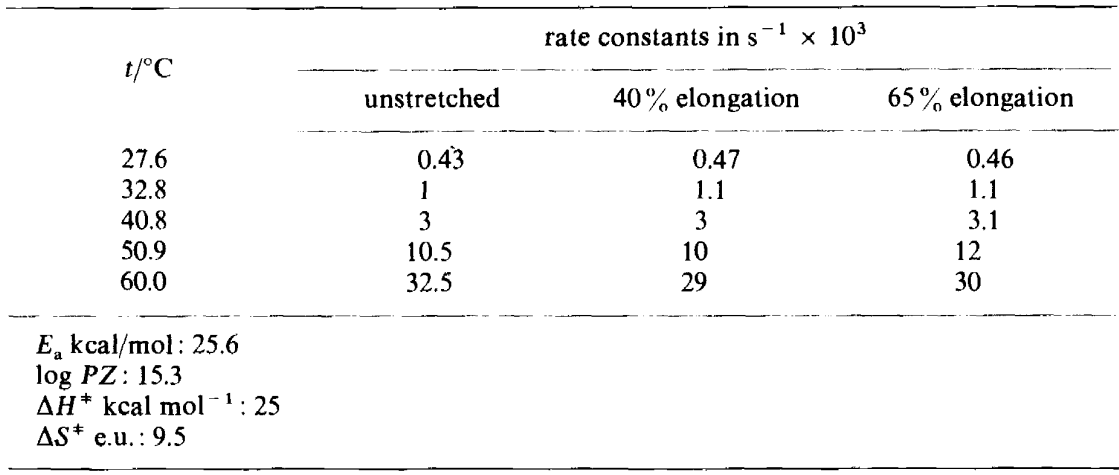

The rate constants have to be compared with the $k_{2}$ values of the unstretched copolymer $C$; they are about 30 per cent higher, but the activation energy and pre-exponential term of the Arrhenius equation are sensibly equivalent. These experimental results confirm once again the role of the incorporation of the photochrome into the polymer chain and the prime importance particularly of their sites of attachment.

\section{CONCLUSION}

Photochromic poly(ethyl acrylate) networks crosslinked with bis(spirobenzopyran methacrylates) undergo, by irradiation in strictly isothermal conditions, a photomechanical contraction. Thermal recovery occurs in the dark; these phenomena are reversible. This photocontractile behaviour is attributed to an entropy increase of the polymeric chain, due to the higher flexibility of the open-ring merocyanines compared to the stiffness of the parent ring-closed spiropyrans. Orientation of photochromic polymer networks causes an important decrease of the decolouration rate, as far as the photochromes are involved in the crosslinks.

\section{ACKNOWLEDGEMENT}

The authors are indebted to the Ministry of Scientific Development for laboratory equipment and to the Centrum voor Hoogpolymeren, IWONL, Agfa-Gevaert for a fellowship (to FDB) and financial support to the laboratory. 


\section{G. SMETS AND F. DE BLAUWE}

\section{REFERENCES}

1 G. Smets, in Reactions on Polymers, ed. J. A. Moore, pp 371-394. D. Reidel:Dordrecht-Holland/ Boston, USA (1973).

2 C. S. Paik and H. Morawetz, Macromolecules, 5, 171 (1972).

${ }^{3}$ G. Smets. Pure Appl. Chem. 30, 1 (1972).

4 G. Smets and G. Evens, Pure Appl. Chem., Macromolecular Chemistry-8. 357 (1973).

${ }^{5}$ See references sub (1)

${ }^{6}$ F. Agolini and F. P. Gray, Macromolecules, 3, 349 (1970).

7 G. Van der Veen and W. Prins, 23rd IUPAC Congress Boston 1971. Macromolecular preprints I, p. 70.

8 G. Van der Veen and W. Prins, Nature, physical science, 230, 69 (1971).

${ }^{9}$ G. Van der Veen, Pd.D. Thesis Univ. Groningen (Netherlands) (1972).

${ }^{10}$ G. M. Brown, Techniques of Chemistry, vol. 3, photochromism, Wiley: New York (1971) pp. 49-288.

11 P. J. Flory, Principles of Polymer Chemistry, Ithaca, New York, Cornell University Press, (1953) p. 579. 